Abstracted/indexed in Academic Search Complete, Asia Journals Online, Bangladesh Journals Online, Biological Abstracts, BIOSIS Previews, CAB Abstracts, Current Abstracts, Directory of Open Access Journals, EMBASE/Excerpta Medica, Google Scholar, HINARI (WHO), International

\title{
Corosolic acid induces potent anti-cancer effects in CaSki cervical cancer cells through the induction of apoptosis, cell cycle arrest and $\mathrm{PI3K} /$ Akt signalling pathway
}

\author{
Yong Qian Xu' ${ }^{1}$, Jian Hai Zhang ${ }^{2}$ and Xing Sheng Yang1 \\ ${ }^{1}$ Department of Gynecology, Qilu hospital of Shandong university, Jinan 250 012, China; ${ }^{2}$ Department of \\ Gynecology, Shengli Oilfield Central Hospital, Dongying 257 034, China.
}

\begin{tabular}{|c|c|}
\hline \multicolumn{2}{|l|}{ Article Info } \\
\hline Received: & 22 February 2016 \\
\hline Accepted: & 21 March 2016 \\
\hline Available Online: & 10 April 2016 \\
\hline \multicolumn{2}{|c|}{ DOI: 10.3329/bjp.v11i2.26793 } \\
\hline \multicolumn{2}{|c|}{$\begin{array}{l}\text { Cite this article: } \\
\text { Xu YQ, Zhang JH, Yang XS. Corosolic } \\
\text { acid induces potent anti-cancer effects } \\
\text { in CaSki cervical cancer cells through } \\
\text { the induction of apoptosis, cell cycle } \\
\text { arrest and PI3K/ Akt signalling path- } \\
\text { way. Bangladesh J Pharmacol. 2016; } \\
\text { 11: 453-59. }\end{array}$} \\
\hline
\end{tabular}

\begin{abstract}
The main objective of the present study was to investigate the anti-tumor activity of corosolic acid in CaSki human cervical cancer cells. Fluorescence and phase contrast microscopic techniques were used to study the effect of the compound on cellular morphology and apoptosis. Results revealed that corosolic acid exerted potent, dose- and time-dependent growth inhibitory effects in CaSki cell proliferation. Cells got detached from one another making clusters of small number of cells floating in the medium. After the cells were treated with 10, 50 and $100 \mu \mathrm{M}$ concentrations of corosolic acid, cells began to emit orange red fluorescence more heavily at the centre of cells indicating apoptosis. Corosolic acid also induced G2/M cell cycle arrest in a dosedependent manner. Increasing doses of corosolic acid treatment to these cells resulted in significant and dose-dependent down-regulation of PI3K and Akt protein expressions.
\end{abstract}

\section{Introduction}

Natural products continue to play a leading role as novel and promising anti-cancer chemotherapeutic agents. They are used as anti-cancer agents either in their natural form or as synthetic or semi-synthetic derivatives. There are plenty of examples of anti-cancer agents from nature including vinca alkaloids, taxanes, camptothecins, the epipodophyllotoxins etc. In addition, there are many anti-cancer candidates from natural sources which are currently in clinical development or have been recently approved for clinical use. Among all the anti-cancer agents approved so far, natural product based anti-cancer agents constitute around $60-65 \%$ of the total (Kinghorn, 2008; Cragg et al., 2005; Newman and Cragg, 2007; Butler, 2008). Natural products are embellished with their inherent drug likeness and as such most of these compounds have a better receptor-binding tendency (Feher and Schmidt, 2003).
Cancer, which involves uncontrolled growth of abnormal cells in the body, has become a major health problem with its rate of incidence as well as rate of mortality still increasing all the time throughout the globe. A promising anti-cancer agent is the one which can selectively target a cancerous cell without causing too much or no damage to the normal cells.

Various anti-cancer agents are known which can achieve this selectivity through the process of apoptosis induction. Apoptosis, which is also known as programmed cell death, is a highly organized biochemical process to eliminate unwanted cells from the body maintaining homeostasis in multi-cellular organisms. Apoptosis process is characterized by various morphological and biochemical indicators including cell shrinkage, membrane blebbing, chromatin condensation and apoptotic body formation (Taraphdar et al., 2011). Several natural products are known to induce apoptosis in a wide variety of cancer cells. 
Apoptosis induction is an important mechanism of anticancer action of many anti-tumor agents (Srivastava et al., 2005). Apoptotic induction has been a novel target for pioneering mechanism-based drug discovery. As such there is a pressing need to screen agents from plants which can induce apoptosis in cancer cells.

The objective of the present study was to evaluate the anti-cancer and apoptotic effects of corosolic acid in CaSki cervical cancer cells. The current study also demonstrated the effect of this compound on cell cycle phase distribution, mitochondrial membrane potential loss and PI3K/Akt signalling pathway. The present report constitutes the first such report on this compound against this cell line.

\section{Materials and Methods}

\section{Materials and reagents}

Corosolic acid, 3-(4,5-dimethylthiazol-2-yl)-2,5-diphenyltetrazolium bromide (MTT), propidium iodide, acridine orange, Hoechst 33258 were purchased from Sigma Chemical Co. (USA). Corosolic acid was dissolved in dimethyl sulfoxide at a stock solution of $100 \mathrm{mM}$ and stored at $-20^{\circ} \mathrm{C}$. Dulbecco's Modified Eagle's Medium, RPMI 1640 medium, Triton X-100 were obtained Hangzhou Sijiqing Biological Engineering Materials Co., Ltd. (China). Fetal bovine serum (FBS) was obtained from Gibco BRL (USA). Phosphorylated p-PI3K, PI3K, p-Akt and Akt were procured from Cell Signalling Technology (USA), while as X-ray film for chemiluminescent system was obtained from Fuji Photo Film (Japan).

\section{Cell line and cell culture conditions}

The CaSki cervical cancer cells were purchased from the Shanghai Institute of Cell Resource Center of Life Science (China). The cells were cultured in Minimum Essential Medium (MEM) and RPMI supplemented with $10 \%$ (v/v) fetal bovine serum (FBS) under humidified atmosphere of $5 \% \mathrm{CO}_{2}$ at $37^{\circ} \mathrm{C}$. The medium was replaced every 3 days. Cells were sub-cultured every 4 days.

\section{Cell proliferation assay}

The cytotoxic effect of corosolic acid against CaSki cervical cancer cells was evaluated by MTT assay. In brief, cells were plated at a density of $2 \times 10^{6}$ cells/well. After 24 hours incubation, cells were treated with corosolic acid $(0,10,20,50$, and $100 \mu \mathrm{M})$ for 24 and 48 hours, MTT solution $(20 \mathrm{mg} / \mathrm{mL})$ was then added to each well. The formazan precipitate was dissolved in $200 \mu \mathrm{L}$ dimethyl sulfoxide and the absorbance was measured in Automated Microplated Reader (Bio-Tek, USA) at $570 \mathrm{~nm}$. The cell viability ratio was calculated by the following formula:
Inhibitory ratio $(\%)=\left(\mathrm{OD}_{\text {control }}-\mathrm{OD}_{\text {treated }}\right) / \mathrm{OD}_{\text {control }} \times$ $100 \%$

Cytotoxicity was expressed as the concentration of corosolic acid inhibiting cell growth by $50 \% \quad\left(\mathrm{IC}_{50}\right.$ value).

\section{Phase contrast microscopic evaluation of cell morpho-} $\log y$

CaSki human cervical cancer cells were plated in 6-well plates at a density of $2 \times 10^{5}$ cells $/ \mathrm{mL}$ and then cultured for 24 hours. Afterwards, the cells were treated with several concentrations of corosolic acid $(0,10,50$ and $100 \mu \mathrm{M})$ for 48 hours. Subsequent to drug treatment, culture plates were examined using a phase contrast light microscope (Olympus, Olympus Optical Co., Ltd., Japan) and images were captured. Dimethyl sulfoxide was used as a negative control. The same spot of cells was marked and captured. The images were captured at a magnification of 200x.

\section{Fluorescence microscopy using acridine orange and Hoechst 33258 staining dyes}

CaSki human cervical cancer cells were plated on a chamber slide at a density of $2 \times 10^{5}$ cells per chamber. The cells were treated with $0,10,50$ and $100 \mu \mathrm{M}$ doses of corosolic acid and then incubated for 48 hours. Subsequently, $20 \mu \mathrm{g} / \mathrm{mL}$ of acridine orange and $20 \mu \mathrm{g} /$ $\mathrm{mL}$ of propidium iodide were added to each chamber before the images were captured by a UV fluorescence microscope (Olympus, Olympus Optical Co., Ltd., Japan) using UV filter at 200x magnification to detect morphological evidence of apoptosis. Further, after treating cells with $0,10,50$ and $100 \mu \mathrm{M}$ doses of corosolic acid, the cells were washed with PBS and fixed with $2.5 \%$ formaldehyde for $30 \mathrm{~min}$. After that the cells were again washed removing the fixing solution and then stained with Hoechst 33258. The cells were again washed before analysis under a fluorescence microscope (Olympus, Japan).

\section{Cell cycle analysis}

Briefly, CaSki human cervical cancer cells $\left(2 \times 10^{5}\right.$ cells $/$ $\mathrm{mL}$ ) were seeded into each well of 6-well plates and incubated for 24 hours for cell adherence. The cells were treated with different concentrations $(0,10,50$ and 100 $\mu \mathrm{M})$ of corosolic acid for 48 hours. After incubation for 48 hours, the cells were harvested and fixed with icecold $70 \%$ ethanol $(5 \mathrm{~mL})$ at $-20^{\circ} \mathrm{C}$ for 1 hour. Before analysis, the cells were washed with cold PBS and resuspended in $460 \mu \mathrm{L}$ of PBS, $20 \mu \mathrm{L}$ propidium iodide and $20 \mu \mathrm{L}$ RNase A. The cells were finally examined by flow cytometry (Becton-Dickinson FACS Calibur flow cytometry) equipped with Cell Quest 3.3 software.

\section{Western blot (Video clip)}

CaSki human cervical cancer cells were treated with 0 , 10, 50 and $100 \mu \mathrm{M}$ dose of corosolic acid and then 
incubated for 48 hours. The adherent and floating cells were harvested and then washed three times with PBS and then lysed in RIPA buffer and protease inhibitor for $20 \mathrm{~min}$. After centrifugation, the protein content was determined by BCA method for Western blotting analysis. The protein lysates $(20 \mu \mathrm{g} /$ lane $)$ were separated by $10 \%$ SDS-PAGE and blotted onto nitrocellulose membranes (Millipore, USA). Each membrane was blocked with $6 \%$ skim milk, and then incubated with the designated primary antibodies overnight at $4^{\circ} \mathrm{C}$. Subsequently, the membrane was incubated with the secondary antibodies (HRP-conjugated goat anti-rabbit or goat anti-mouse IgG) for 1 hour at room temperature and then visualized by Western blotting detection reagents (Trans Gene, China).

\section{Statistical analysis}

The results represent values from three independent experiments with the data expressed as the means \pm SD. Differences between the control and treatment groups were examined using one-way ANOVA. Significance of difference was indicated as a $\mathrm{p}<0.05$, ${ }^{\mathrm{b}} \mathrm{p}<0.01$.

\section{Results}

\section{Anti-tumor activity}

Corosolic acid is a pentacyclic triterpene acid found in many plants including lagerstroemia speciosa. Its structure is given in Figure 1 while as its anti-proliferative effects in CaSki cervical cancer cells is shown in Figure 2. The results suggest that CaSki cervical cancer cells when treated with increasing doses of corosolic acid, a dose-dependent growth inhibition was observed. It was also seen that this growth inhibition also increased with increasing incubation times to which these cells were kept. Thus, corosolic acid exhibited dose- and timedependent cytotoxic effect in CaSki cervical cancer cells.

\section{Cell morphology}

Initially, phase contrast microscopy was used to investigate the cell morphological effects of corosolic acid. The results of phase contrast microscopy are depicted in Figure 3A-D which indicated that in contrast to untreated control cells which revealed normal cell morphology and exhibited total attachment to one another, the corosolic acid-treated cells showed irregular morphology with clustering of cells and detachment from one another. Decrease in the cell population was observed with the increase in the corosolic acid concentration. Untreated CaSki cells seemed as densely packed multi-layers, whereas after incubation with various concentrations of corosolic acid for 48 hours

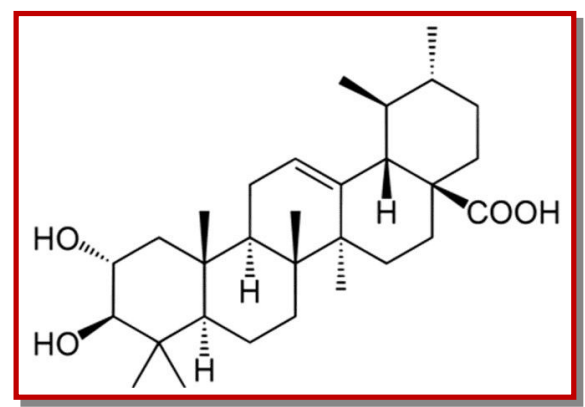

Figure 1: Chemical structure of corosolic acid- a pentacyclic triterpene acid

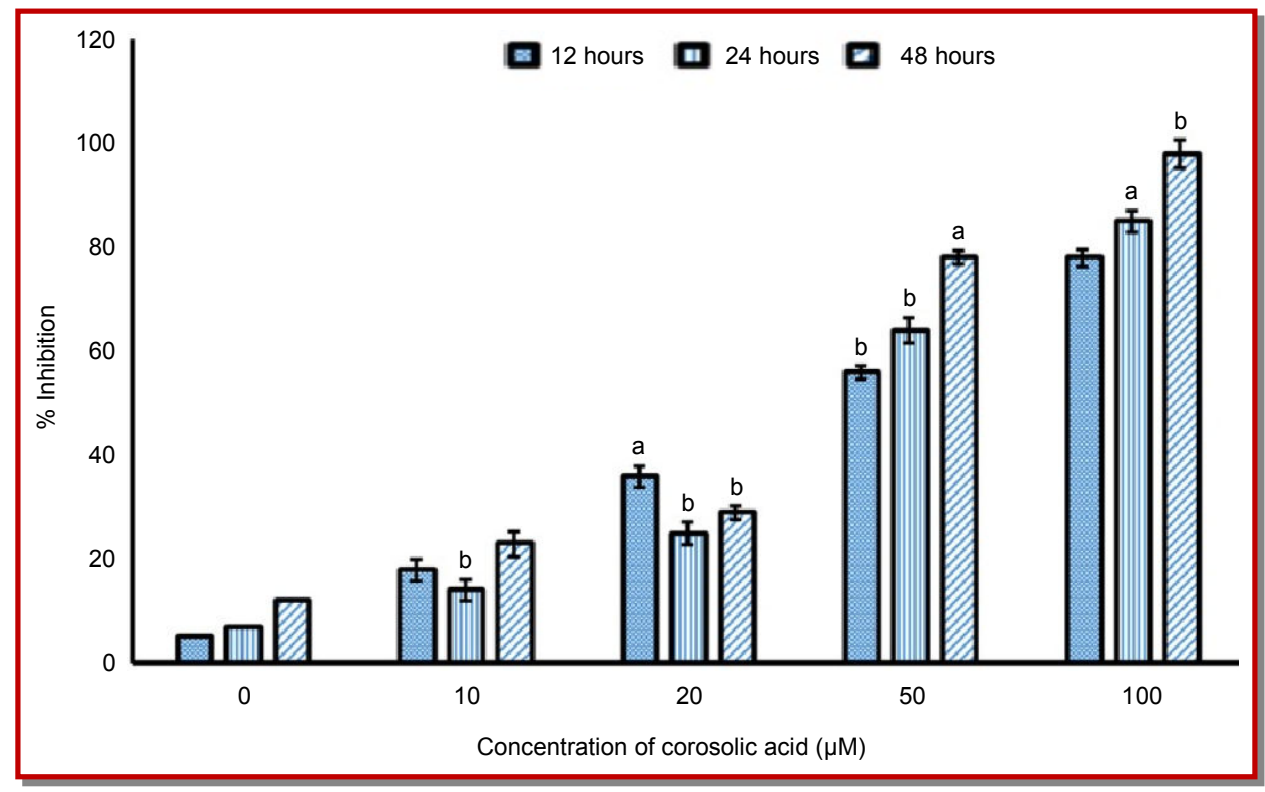

Figure 2: Growth inhibitory effect of corosolic acid in human cervical cancer cells (CaSki) at increasing doses. Data are shown as the mean $\pm \mathrm{SD}$ of three independent experiments. ${ }^{\mathrm{a}} \mathrm{p}<0.05$, ${ }^{\mathrm{b}} \mathrm{p}<0.01$, vs $0 \mu \mathrm{M}$ (control). MTT assay was used to evaluate the cell cytotoxicity of this compound 

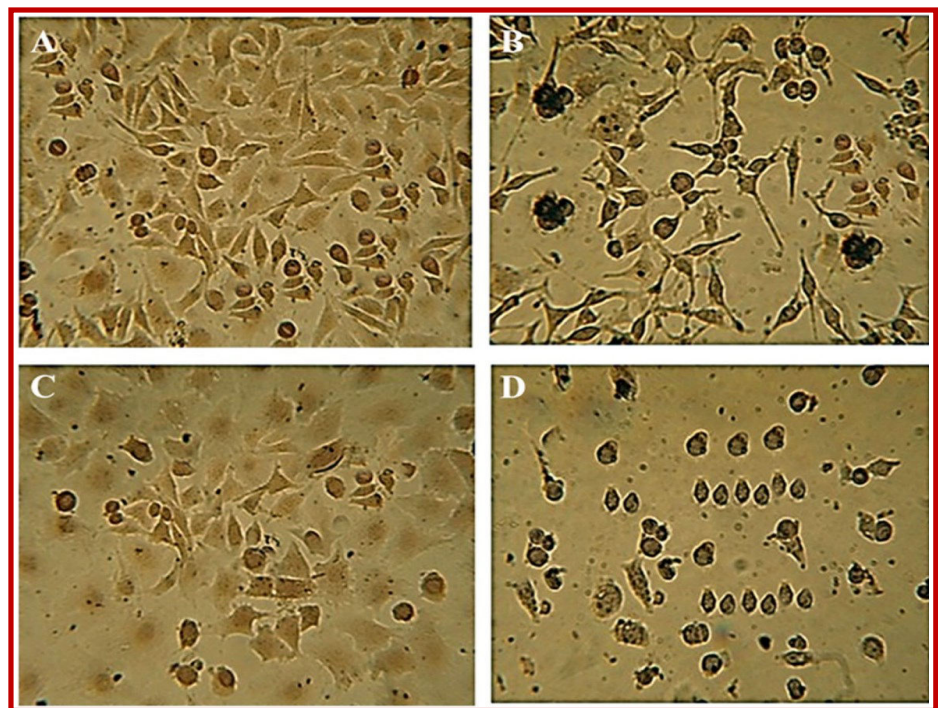

Figure 3: Effects of corosolic acid on the morphology of CaSki cervical cancer cells. Morphological changes were observed under the phase-contrast microscopy after treating without (A, control) and with 10 (B), 50 (C) and $100 \mu \mathrm{M}$ (D) of corosolic acid for 48 hours

several of the cells became shrunken and detached from each other.

\section{Induction of apoptosis}

Acridine orange-propidium iodide staining and membrane-permeable Hoechst 33258 (a blue fluorescent dye) staining were also performed to examine the apoptosisinducing effects of corosolic acid on CaSki human cervical cancer cells. Acridine orange-propidium iodide double staining showed that corosolic acid induced potent apoptotic features. The untreated cells indicated homogenous green fluorescence (Figure 4A) while as the drug-treated cells treated with 10, 50 and $100 \mu \mathrm{M}$ dose exhibited orange red fluorescence and the intensity of this fluorescence increased with increasing dose (Figure 4B-D). Acridine orange can be used in conjunction with propidium iodide to differentiate between viable, apoptotic and necrotic cells.

Similar results were obtained using Hoechst 33258 staining and these results are shown in Figure 5A-D, and indicate that unlike untreated control cells which showed normal morphology, drug-treated cells exhibi-
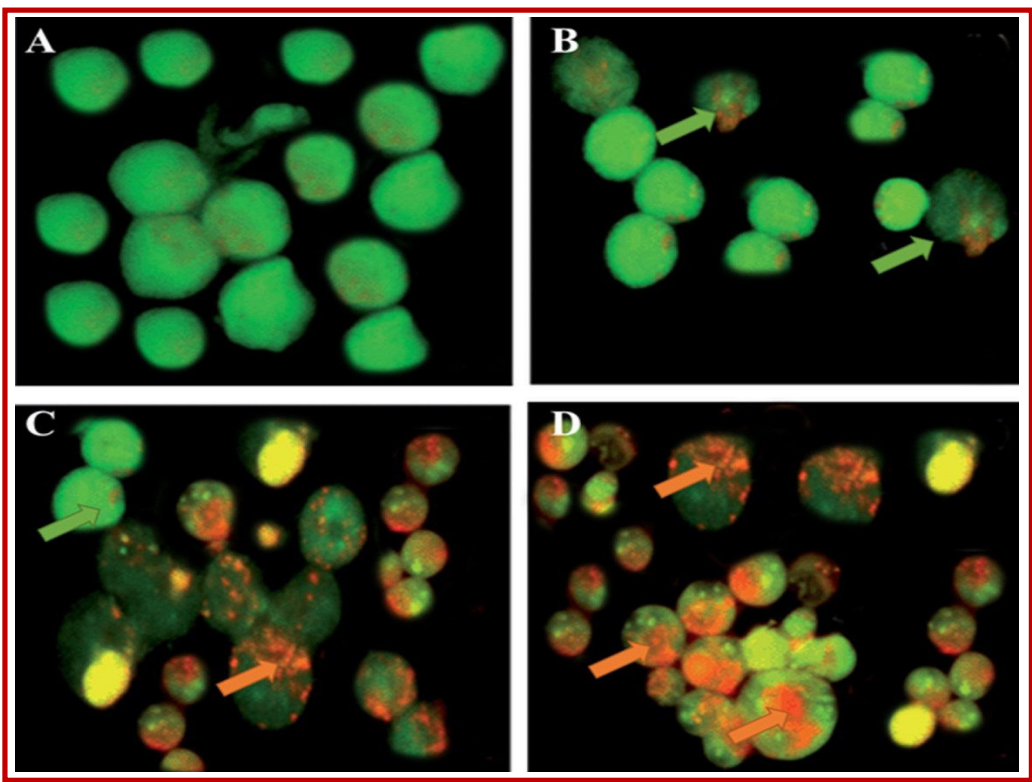

Figure 4: Fluorescence microscopy study of CaSki cervical cancer cells using acridine orange/propidium iodide (AO/PI) staining. The cells were treated without (A, untreated control), and with 10, 50 and $100 \mu \mathrm{M}$ of corosolic acid for 48 hours. Early and late apoptotic cells are shown by green and orange arrows respectively 


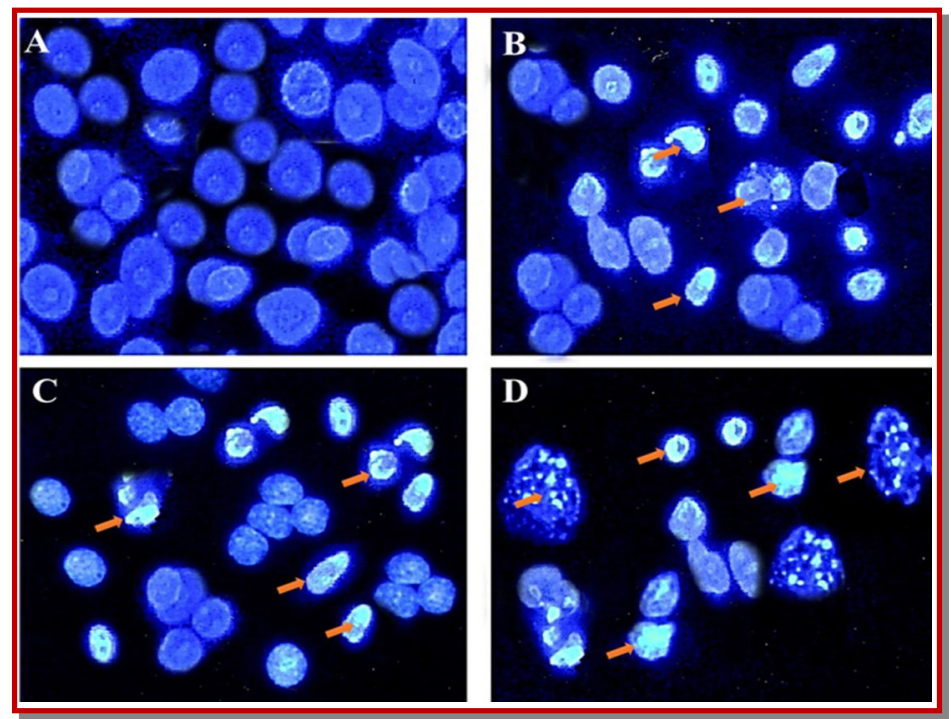

Figure 5: Corosolic acid induces apoptotic morphological features in CaSki cervical cancer cells. The cells were treated without (A, untreated control), and with 10,50 and $100 \mu \mathrm{M}$ of corosolic acid for 48 hours. The orange arrows represent cells which have undergone apoptosis. The images were captured using a fluorescence microscope

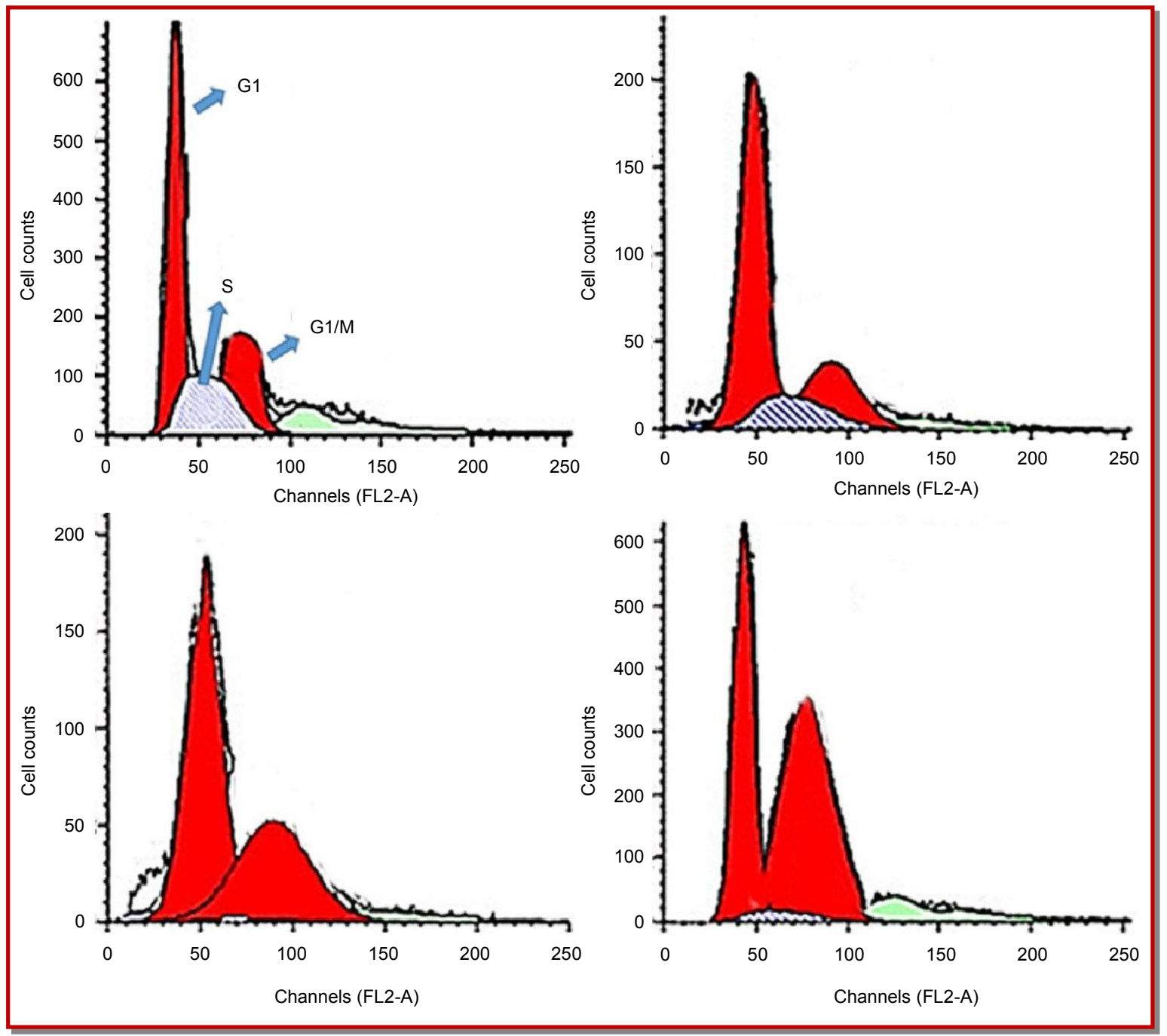

Figure 6: Corosolic acid induced G2/M cell cycle arrest in CaSki cervical cancer cells. Flow cytometry in combination with propidium iodide was used to evaluate the effect of corosolic acid on cell cycle phase distribution in CaSki cells after the cells were treated without $0 \mu \mathrm{M}(\mathrm{A})$, with 10,50 and $100 \mu \mathrm{M}$ of corosolic acid for 48 hours 


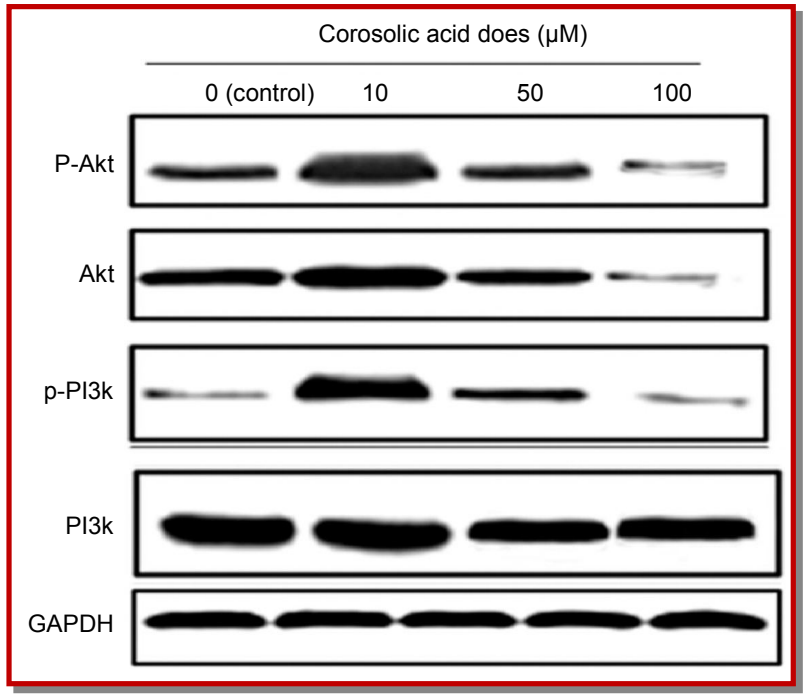

Figure 7: Corosolic acid targets PI3K/Akt signalling pathway in CaSki cervical cancer cells. Western blot assay was used to detect the changes in protein expressions. The cells were treated with 10, 50 and $100 \mu \mathrm{M}$ dose of corosolic acid and it was seen that there was a down-regulation of PI3K/Akt protein expressions

ted evident signs of apoptosis including membrane blebbing, chromatin condensation, DNA cleavage. Light blue nuclei could be seen under fluorescence microscopy in case of untreated cells, while as apoptotic cells displayed bright blue fluorescence due to karyopyknosis and chromatin condensation.

\section{G2/M phase cell cycle arrest}

The effect of corosolic acid on cell cycle phase distribution was evaluated by flow cytometry and the results are shown in Figure 6A-D. As compared to the untreated cells, corosolic acid-treated cells indicated that the percentage of cells in the G2/M phase of the cell cycle increased from 34.5 to $67.2 \%$ with different doses of the drug. This increase in the percentage of G2/M phase cells was accompanied by a corresponding decrease in the percentage of S-phase cells. Overall, corosolic acid had the tendency to induce G2/M phase cell cycle arrest in dose-dependent manner.

\section{PI3K/Akt signalling pathway}

The effect of corosolic acid on the PI3K/Akt signalling pathway was examined by Western blot method in order to fully understand the molecular mechanism of action behind the anti-cancer activity of corosolic acid in CaSki cervical cancer cells. The results which are shown in Figure 7 indicate that increasing doses of corosolic acid treatment to these cells resulted in significant and dose-dependent down-regulation of PI3K and Akt protein expressions. Corosolic acid treated cells exhibited decreased phosphorylation of PI3K and Akt which indicate its ability to inhibit the central cancer pathway.

\section{Discussion}

Triterpenoids are the natural compounds composed of three terpene units with the molecular formula $\mathrm{C}_{30} \mathrm{H}_{48}$ and are synthesized by plants by the cyclization of squalene. Many triterpenoids including betulinic acid, maslinic acid, ursolic acid, pomolic acid, oleanolic acid have been reported to exhibit anti-tumor properties (Xin et al., 2008; Fernandes et al., 2005; Reyes Zurita et al., 2009; Martin et al., 2007). Corosolic acid (Molecular formula $\mathrm{C}_{30} \mathrm{H}_{48} \mathrm{O}_{4}$ ) is an ursane type triterpene and is the main component of banana leaves. This compound has been reported to exhibit a wide range of pharmacological activities including anti-diabetic and antitumor properties (Sivakumar et al., 2009). Corosolic acid has been shown to enhance the anti-tumor effects of chemotherapy in ovarian tumor cells by suppressing signal transducer and activator of transcription 3 signaling (STAT3). Compounds that inhibit STAT3 signalling pathway are promising anti-cancer candidates and many of those compounds are currently in clinical trials for the treatment of malignant cancers (Page et al., 2011; Fujiwara et al., 2013). Corosolic acid has been shown to inhibit the cell proliferation of osteosarcoma and glioblastoma cancer cells. The compound has been found to exert both in vitro and in vivo effects in suppressing subcutaneous tumor development and lung metastasis in a mouse model of osteosarcoma (Fujiwara et al., 2011; Horlad et al., 2013).

To the best of our knowledge, there are no previous reports on the anti-cancer effects of corosolic acid in CaSki cervical cancer cells. In the present study, our aim was to evaluate the anti-cancer potential of corosolic acid against CaSki cervical cancer cells by studying its effect on apoptosis induction, cell cycle arrest and PI3K/Akt signalling pathway. Corosolic acid exerted potent, dose- and time-dependent growth inhibitory effects in CaSki cell proliferation. On treating with different doses of corosolic acid for 48 hours, phase contrast microscope revealed that the cells got detached from one another making clusters of small number of cells floating in the medium. Corosolic acid treated cells began to emit orange red fluorescence indicating the onset of apoptosis in these cells. Corosolic acid also induced G2/M cell cycle arrest in a dose-dependent manner. Increasing doses of corosolic acid treatment to these cells results in significant and dose-dependent down-regulation of PI3K and Akt protein expressions. 


\section{Conclusion}

Corosolic acid exerts potent anti-cancer effects in CaSki cervical cancer cells via apoptosis induction, G2/M cell cycle arrest and down-regulation of PI3K/Akt signalling pathway.

\section{Conflict of Interest}

The authors declare that there is no conflict of interest to reveal.

\section{References}

Butler MS. Natural products to drugs: Natural productderived compounds in clinical trials. Nat Prod Rep. 2008; 25: 475-516.

Cragg GM, Kingston DGI, Newman DJ (eds). Anti-cancer agents from natural products. Florida, CRC Press/Taylor and Francis, 2005.

Feher M, Schmidt JM. Property distributions: Differences between drugs, natural products and molecules from combinatorial chemistry. J Chem Inf Comput Sci. 2003; 43: 21827.

Fernandes J, Weinlich R, Castilho RO, Kaplan MA, AmaranteMendes GP, Gattass CR. Pomolic acid triggers mitochondria dependent apoptotic cell death in leukemia cell line. Cancer Lett. 2005; 219: 49-55.

Fujiwara Y, Komohara Y, Ikeda T, Takeya M. Corosolic acid inhibits glioblastoma cell proliferation by suppressing the activation of signal transducer and activator of transcription3 and nuclear factor-kappa B in tumor cells and tumorassociated macrophages. Cancer Sci. 2011; 102: 206-11.

Fujiwara Y, Takaishi K, Nakao J, Ikeda T, Katabuchi H, Takeya M, Komohara Y. Corosolic acid enhances the anti-tumor effects of chemotherapy on epithelial ovarian cancer by inhibiting signal transducer and activator of transcription 3 signaling. Oncol Lett. 2013; 6: 1619-23.

Horlad H, Fujiwara Y, Takemura K, Ohnishi K, Ikeda T, Tsukamoto H, Mizuta H, Nishimura Y, Takeya M, Komohara Y. Corosolic acid impairs tumor development and lung metastasis by inhibiting the immunosuppressive activity of myeloid-derived suppressor cells. Mol Nutr Food Res. 2013; 57: 1046-54.

Kinghorn AD. Drug discovery from natural products. In: Foye's Principles of medicinal chemistry. Lemke TL, Williams DA (eds). 6th ed. Philadelphia, Wolters Kluwer/ Williams and Wilkins, 2008, pp 12-25.

Martin R, Carvalho J, Ibeas E, Hernandez M, Ruiz Gutierrez V, Nieto ML. Acidic triterpenes compromise growth and survival of astrocytoma cell lines by regulating reactive oxygen species accumulation. Cancer Res. 2007; 67: 3741-51.

Newman DJ, Cragg GM. Natural products as sources of new drugs over the last 25 years. J Nat Prod. 2007; 70: 461-67.

Page BD, Ball DP, Gunning PT. Signal transducer and activator of transcription 3 inhibitors: A patent review. Expert Opin Ther Pat. 2011; 21: 65-83.

Reyes Zurita FJ, Rufino Palomares EE, Lupianez JA, Cascante M. Maslinic acid, a natural triterpene from Olea europaea L., induces apoptosis in HT29 human colon-cancer cells via the mitochondrial apoptotic pathway. Cancer Lett. 2009; 273: 4454.

Sivakumar G, Vail DR, Nair V, Medina-Bolivar F, Lay JO Jr. Plant-based corosolic acid: Future anti-diabetic drug? Biotechnol J. 2009; 12: 1704-11.

Srivastava V, Negi AS, Kumar JK, Gupta MM, Khanuja SP. Plant-based anti-cancer molecules: A chemical and biological profile of some important leads. Bioorg Med Chem. 2005; 13: 5892-908.

Taraphdar AK, Roy M, Bhattacharya RK. Natural products as inducers of apoptosis: Implication for cancer therapy and prevention. Curr Sci. 2011; 80.

Xin HL, Yue XQ, Xu YF,Wu YC, Zhang YN, Wang YZ, Ling CQ. Two new polyoxygenated triterpenoids from Actinidia valvata. Helv Chim Acta. 2008; 91: 575-80. 


\section{Your feedback about this paper}

1. Number of times you have read this paper 0

2. Number of times you have seen the video clip 0

3. Which video you may need to see again, if any

4. Quality of paper
Excellent
$\bigcirc$ Good
Moderate
Not good

5. Your comments 